\title{
The effect of urbanization on the functional and scale-sensitive diversity of bird assemblages in Central India
}

\author{
Manoj Kale ${ }^{1}$, Nandkishor Dudhe ${ }^{2}$, Marco Ferrante ${ }^{3}$, Tatiana Ivanova ${ }^{4}$, Raju Kasambe ${ }^{2}$, \\ Irina S. Trukhanova ${ }^{5}$, Prosun Bhattacharya ${ }^{1}$ and Gabor L. Lövei ${ }^{3, *}$ \\ ${ }^{1}$ Department of Sustainable Development and Environmental Science and Engineering, KTH Royal Institute of Technology, Teknikringen, 76, SE-100 44, Stockholm, \\ Sweden \\ ${ }^{2}$ Bombay Natural History Society, Hornbill House, Shaheed Bhagat Singh Road, Mumbai, 400001, Maharashtra, India \\ ${ }^{3}$ Department of Agroecology, Aarhus University, Flakkebjerg Research Centre, Fors øgsvej 1, DK-4200 Slagelse, Denmark \\ ${ }^{4}$ ICPO 'Biologists for Nature Conservation', 24 line V. O. 3-7, 199106 St Petersburg, Russia \\ ${ }^{5}$ Applied Physics Laboratory, Polar Science Center, University of Washington, 1013 NE 40th St., Seattle, WA 98105, USA \\ (Received 5 April 2018; revised 28 August 2018; accepted 28 August 2018; first published online 26 September 2018)
}

\begin{abstract}
Diversity changes can be evaluated at various spatial scales, and the relationship between changes in diversity at the local, landscape and regional scales is not evident. The overall patterns of functional and beta diversity of bird assemblages were evaluated along a five-stage urbanization gradient, censused over the months of January to April in the years 2010-2013, in and around Amravati city, Deccan Plateau, Central India. We expected the abundance of large and predatory species to decline along the gradient, and urbanization to homogenize species richness at the landscape level. Overall, 112,829 birds belonging to 89 species were identified in the region, and species richness decreased from the rural forest ( 73 species) to more urbanized areas (lowest at the centre of Amravaty city with 29 species). Along the urbanization gradient, bird assemblages contained more small species, and the share of frugivorous and omnivorous species also increased, while that of insectivorous species decreased. Diversity partitioning indicated that of the overall pattern, local (alpha) diversity accounted for $50.1 \%$ of the total (gamma) diversity, and urbanization stages another $36.2 \%$; the contribution of within-stage, local diversity was rather small (2.7\%), indicating fairly homogeneous assemblages.
\end{abstract}

Key Words: anthropogenic activities, Aves, biotic homogenization, disturbance, forest-urban gradient, frugivory, Indian Peninsula, omnivory, scale-sensitive diversity, size effects

\section{INTRODUCTION}

Urbanization dramatically transforms natural environments, perpetuating habitat loss and fragmentation worldwide and changing the original flora and fauna, but also concentrating resources and energy (Wagner 2008). Together with increased density of humans, urbanized areas have higher temperatures, modified precipitation regimes, altered nutrient cycling and increased concentration of various xenobiotics (McKinney 2006). Urbanization also promotes biotic homogenization, as only a few, usually non-native, species can tolerate the urban conditions (McKinney 2006). As more than half of the world's population lives in cities (United Nations 2014), urban biodiversity is particularly valuable, both

\footnotetext{
*Corresponding author. Email: gabor.lovei@agro.au.dk
}

as a link between humans and nature and for providing ecosystem services (Millennium Ecosystem Assessment 2005).

In general, higher levels of urbanization cause a decline in ecosystem services (Eigenbrod et al. 2011, Ferrante et al. 2014) and in biodiversity (see Ahrné et al. 2009 for bumble bees; McKinney 2008 for plants; Marzluff 2001 for invertebrates and vertebrates excluding birds; Sol et al. 2014 for birds), although negative effects are not universal (Magura et al. 2010, Marzluff 2005, McKinney 2008).

Birds are a flagship group in studies of urbanization on biodiversity, being a favoured group by many people, taxonomically well-known, and quick to react to environmental changes in easily detectable ways (Chazdon et al. 2009, Gibson et al. 2011). Bird densities show both negative (Aronson et al. 2014) and positive (Galushin 1971, Marzluff 2001, Sengupta et al. 2014) responses 
to urbanization, and avian species richness can decrease with increasing urbanization (Chace \& Walsh 2006), or peak at intermediate levels of urbanization (Jokimäki \& Suhonen 1993, Marzluff 2005).

Our knowledge on the effects of urbanization on birds originates mostly from studies in the northern hemisphere (Aronson et al. 2014), while most biodiversity resides at lower latitudes (Huston 1994), where the fastest growth in urbanization also occurs (United Nations 2014). Decreasing bird diversity was detected also in Central America (MacGregor-Fors 2008) and Asia (Lin et al. 2011).

To analyse effects of urbanization on bird assemblages in Central India, we used an urbanization gradient approach (Clergeau et al. 1998, Jokimäki \& Suhonen 1993, Liker et al. 2008) to examine the factors influencing bird assemblages.

We tested the following hypotheses: increasing omnivory and herbivory hypothesis (H1): as urbanization advances, much of the original diversity, including plants and their associated arthropods is destroyed (Wagner 2008), so we expected that raptors and insectivores will decline, and omnivores and plant/seed eaters will increase as urbanization advances. Support for this hypothesis was found when examining the effects of urbanization on ground beetles in Denmark (Elek \& Lövei 2007). We also expected that the average body size of birds will gradually decrease with advancing urbanization (the decreasing body size hypothesis, H2). Urban habitats are characterized by larger and more frequent environmental fluctuations, and higher degrees of disturbance (McKinney 2006), causing smaller windows of opportunity, which can be better exploited by smaller species, and their relative abundance will increase as urbanization advances. Large species are expected to diminish or disappear altogether (Cardillo et al. 2005). Finally, we expected that as urbanization progresses, beta diversity will decrease (H3) - the assemblages will be more similar to each other with fewer local differences. This can be interpreted as a version of the homogenization hypothesis (McKinney 2006): bird assemblages in more urbanized habitats will be less different from each other than in the original, rural, forest-associated habitats.

\section{METHODS}

\section{Study area}

The study was conducted in the area of Amravati city (Figure 1), in the state of Maharashtra, on the Deccan Plateau in Central India $\left(20^{\circ} 56^{\prime}-20^{\circ} 93^{\prime} \mathrm{N}, 77^{\circ} 45^{\prime}-\right.$ $77^{\circ} 75^{\prime} \mathrm{E}, 343 \mathrm{~m}$ asl). This area is characterized by a tropical wet and dry climate with a mean annual temperature of $27^{\circ} \mathrm{C}$, and a mean annual precipitation of $874 \mathrm{~mm}$. The summer lasts from March to June, the monsoon season from July to October, and the winter from November to March. An urbanization gradient of five stages was selected on the basis of built-up surface and vegetation composition, as these two parameters are usually considered reliable indicators of human disturbance level (Pickett et al. 2011). The five-stage gradient included (1) rural forest, (2) industrial, (3) periurban, (4) suburban and (5) urban area $(0 \%, 0-20 \%$, $<35 \%, 35-50 \%,>50 \%$ of built-up area, respectively, identified from Google Earth). Our selected stages were characterized by similar plant communities, although the dominant species were different. The rural forest was a forest reserve $\left(20^{\circ} 53^{\prime} \mathrm{N}, 77^{\circ} 47^{\prime} \mathrm{E}\right)$ classified as Southern Tropical Dry Deciduous Forest by Champion \& Seth (1968), and dominated by Aegle marmelos Correa, Azadiractha indica A.Juss., Butea monosperma Taub., Calotropis procera Aiton, Cassia fistula L. and Gliricidia sepium Kunth. The land between the studied forest reserve and the urbanized area was occupied by rain-fed croplands of mixed cropping. The industrial stage $\left(20^{\circ} 53^{\prime} \mathrm{N}, 77^{\circ} 45^{\prime} \mathrm{E}\right)$ was located at the south-eastern part of Amravati city, comprising an area of 200 ha, which was allocated by the government for industrial development. This area was under construction, and changed considerably for the duration of the study. The roads were tarmac, the average size of individual land parcels much bigger than in other areas. Nevertheless, the plant community was represented by the same dominant tree species during our study: Ailanthus excelsa Roxb., Eucalyptus obliqua L'Herit., Leucaena leucocephala de Wit, Psidium guajava L. and Ziziphus mauritiana Lam. The periurban stage $\left(20^{\circ} 53^{\prime} \mathrm{N}, 77^{\circ} 45^{\prime} \mathrm{E}\right)$ was located at the periphery of Amravati city, with separate houses, plots of land and streets with little or no asphalt; and less than 35\% of the surface was occupied by buildings. Virtually all individual households had gardens and kept domestic animals. The most common plant species were Ficus benghalensis L., Ficus racemosa L., Ficus religiosa L., Lantana camara L., Millettia pinnata Panigrahi and Tamarindus indica $\mathrm{L}$. The suburban stage $\left(20^{\circ} 56^{\prime} \mathrm{N}, 77^{\circ} 46^{\prime} \mathrm{E}\right)$ was a residential area dominated by the tree species Delonix regia Raf. and Michelia champaca L. and by the fruit trees Annona squamosa L., and Mangifera indica L. In this area, $35-50 \%$ of the total surface was covered with tarmac or occupied by buildings. Several individual households kept domestic animals and cultivated vegetable gardens. The urban stage $\left(20^{\circ} 55^{\prime} \mathrm{N}, 77^{\circ} 45^{\prime} \mathrm{E}\right)$ was densely populated, including also the historical centre of the city, and more than $50 \%$ of the surface was covered with buildings. It was characterized by tree species of $A$. indica, Cocos nucifera L., F. religiosa, Polyalthia longifolia Sonn. and Terminalia catappa L. The centre of Amravati was $\sim 6-7 \mathrm{~km}$ from the forest area, $4-5 \mathrm{~km}$ from the 


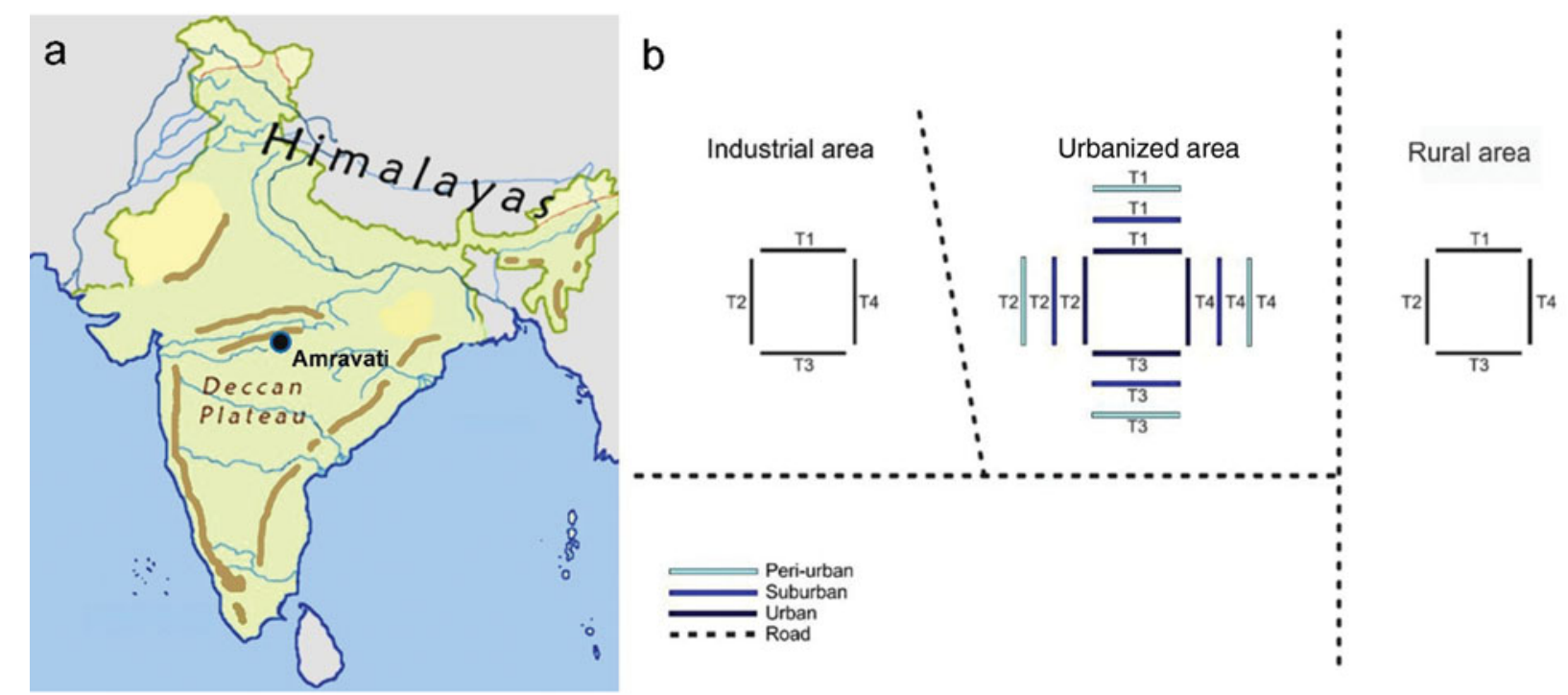

Figure 1. Location of Amravati city, Maharashtra State, on the Deccan Plateau, India (left panel), and the arrangement of census paths (right panel). Transects were indicated by ' $\mathrm{T}$ '.

suburban stage, $2-3 \mathrm{~km}$ from the peri-urban stage and $4-8 \mathrm{~km}$ from the industrial area.

\section{Bird survey methods}

Bird presence and abundance were recorded during the breeding season (January-April), between 2010-2013, along four transects at each of the five urbanization stages (Verner 1985). Each transect was $3 \mathrm{~km}$ long and $50 \mathrm{~m}$ wide, and was walked at the same speed on sunny days from $06 \mathrm{~h} 00$ to $09 \mathrm{~h} 00$ on three days of each of the four months in each of the four years. Identification of birds was done using field guides (Ali 2002, Grimmett et al. 2001). Some species belonging to raptor, quail and warbler families $(5-10 \%$ of the total number of observations) were excluded from the analysis as their species identification was uncertain. Additionally, data on several waterbirds (Actitis hypoleucos L., Amaurornis phoenicurus Pennant, Ardeola grayii (Sykes), Bubulcus ibis L., Egretta garzetta L. and Pseudibis papillosa (Temminck)) were excluded ( $2.6 \%$ of the total number of observations) as not all urbanization stages provided suitable habitat for them.

\section{Statistical analysis}

We selected the maximum numbers counted of each species over the three days of surveys in each month as representative of the bird abundance at that urbanization stage in that month. We tested for significant differences between the four months per year using Wilcoxon paired $t$-tests. As none of the comparisons showed significant differences, we kept the maximum value for each species. Diversity within transect and between urbanization stage was examined using an additive partitioning method (Lande 1996). This method considers $\alpha$ - (i.e. diversity at transect/year level) and $\beta$-diversity as additive components of the $\gamma$ - (i.e. regional) diversity, and express them in the same units of species richness. This allows direct comparisons between $\alpha$ - and $\beta$-diversity within the same study (Crist \& Veech 2006) as well as between studies, when diversity is expressed as proportions (Anderson et al. 2011). As very little (2.7\%) of the diversity was explained by differences among transects within an urbanization stage, we considered only year and urbanization stage as a factor in further analyses. We compared bird species richness for each urbanization stage/year using the Jaccard dissimilarity index (Magurran 2003: Eq. 1).

$$
C_{j}=a /(a+b+c)
$$

Where $a$ is the number of species shared between two urbanization stages, and $b$ and $c$ the number of species found at only one of the stages (Henderson \& Southwood 2016). In order to construct the dendrogram, we used 'average linkage' clustering method (Izenman 2008).

Although N-mixture models are technically appropriate to estimate absolute abundance by incorporating probability of detection (Barker et al. 2017), estimating the actual population size in each stage of the urbanization gradient was not the aim of this study. Moreover, $\mathrm{N}$-mixture models do not perform well under low probabilities of detection (Duarte et al. 2018). Therefore, we tested for differences in species richness and abundance using generalized linear mixed models, with bird size class 


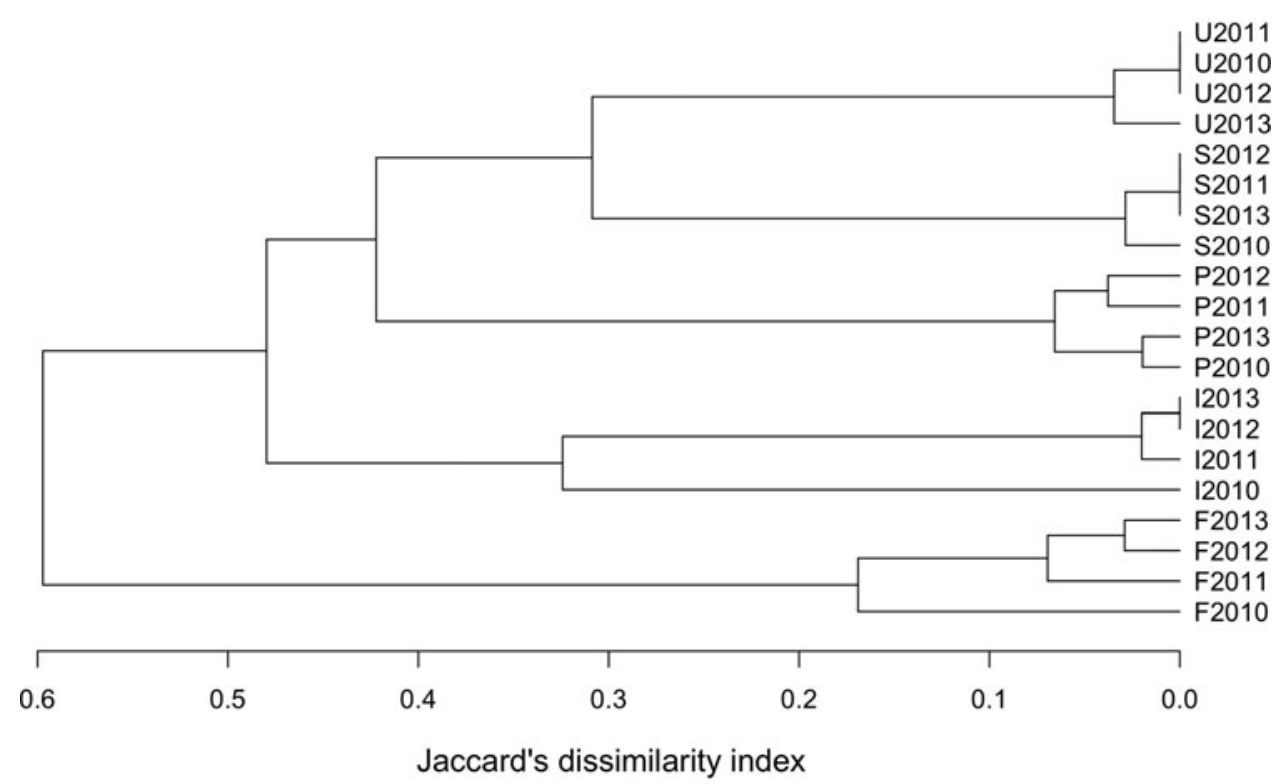

Figure 2. Jacccard's dissimilarity indices for the bird species richness along the five-stage urbanization gradient, observed during censuses in 20102013, in and around Amravati city, Maharashtra State, India.

and foraging preference as random factors. Foraging preferences were categorized as: insectivorous, omnivorous, predatory (when feeding on other vertebrates such as fish or mammals), herbivorous and frugivorous. Bird body size classes (a proxy for several categories of resource use, Peters 1986) were categorized as: small (6-45 g), medium (45-120 g), large (120-300 g) and very large $(>300 \mathrm{~g})$. Both categorizations were based on guilds and categories in Wilman et al. (2014). We tested if species presence/absence and total bird abundance varied along the five-stage gradient between years using binomial and Poisson distributions, respectively. To account for overdispersion, the Poisson GLM standard errors were corrected using a quasi-GLM model where the variance was given by $\phi \times \mu$, where $\mu$ is the mean and $\phi$ the dispersion parameter (Zuur et al. 2009). Model selection was done through backward selection, by comparing AICs. All calculations were made using the R program version 3.0.2, and the package vegan.

\section{RESULTS}

During four years, our study assemblage included 89 bird species along the urbanization gradient, the majority of them were year-round residents (Appendix 1). The total species richness was higher in the rural (forest) and industrial zone stages, followed by the peri-urban, suburban and urban ones $(73,73,54,35$ and 29 species, respectively). However, the number of species in the industrial zone decreased considerably after the first year of census, while the other stages did not show such striking between-year differences (Figure 2). The overall assemblage was composed of insectivorous species (44\%), omnivores $(31 \%)$, predators $(10 \%)$, herbivores $(9 \%)$ and frugivores $(6 \%)$. Considering size distribution, nearly half of the species $(48 \%)$ were small, while $24 \%$ were of medium size, $17 \%$ large and $11 \%$ very large.

If abundance of individuals was considered, we observed almost the opposite of the trend observed for species richness: the urban stage had the highest number (41 670 individuals), followed by the suburban (24409 ind.), peri-urban (17 749 ind.), forest (15 562 ind.) and industrial (13439 ind.) habitats. These values were directly comparable, because of the identical sampling effort at the various urbanization stages. Variation in abundance per year showed idiosyncratic patterns for each of the urbanization stages (Table 1). In the forest area in 2010 we observed fewer individuals than in the subsequent years; while in the industrial zone, the assemblage in 2010 showed a much higher number than later. In 2010, the record of bird individuals in the suburban area was more similar to 2013, due to the presence of large flocks of Hirundo concolor observed in those years. In the peri-urban area, the trend was the same as in the suburban one, but the dominant species was Columba livia throughout the study period. Finally, bird abundance in the urban area in 2010 was closer to 2011 than to the remaining years.

The mean species richness per year of each of the foraging categories was always higher in the rural forest, with the exception of frugivorous species; the same was not found for bird count (Table 1). Along all the stages of the gradient there were more small species than big ones 
Table 1. Species richness and numbers of individuals by foraging category along the urbanization gradient near Amravati city, Maharashtra State, India, censused between 2010 and 2013. Values are yearly means \pm SD.

\begin{tabular}{lccrcc}
\hline Parameter and urbanization stage & Frugivores & Herbivores & Insectivores & Omnivores & Predators \\
\hline Species richness & $2.8 \pm 0.5$ & $7.5 \pm 0.6$ & $28.8 \pm 1.7$ & $19.8 \pm 1.0$ & $8.3 \pm 1.5$ \\
Rural & $5.0 \pm 0.0$ & $5.3 \pm 0.5$ & $21.3 \pm 7.9$ & $18.3 \pm 2.5$ & $5.5 \pm 1.0$ \\
Industrial & $2.0 \pm 0.0$ & $4.0 \pm 0.0$ & $23.3 \pm 0.5$ & $17.3 \pm 0.5$ & $4.8 \pm 0.5$ \\
Peri-urban & $2.0 \pm 0.0$ & $3.0 \pm 0.0$ & $12.0 \pm 0.0$ & $13.3 \pm 0.5$ & $4.0 \pm 0.0$ \\
Suburban & $1.0 \pm 0.0$ & $3.0 \pm 0.0$ & $8.8 \pm 0.5$ & $12.0 \pm 0.0$ & $4.0 \pm 0.0$ \\
Urban & & & & & \\
Numbers of individuals & $22.0 \pm 24.1$ & $60.0 \pm 64.1$ & $14.7 \pm 30.5$ & $39.8 \pm 70.5$ & $4.9 \pm 2.2$ \\
Rural & $14.5 \pm 8.2$ & $20.6 \pm 39.8$ & $11.9 \pm 45.0$ & $43.6 \pm 117$ & $10.7 \pm 27.6$ \\
Industrial & $11.2 \pm 22.0$ & $24.2 \pm 25.8$ & $18.4 \pm 40.7$ & $47.8 \pm 86.4$ & $9.7 \pm 17.0$ \\
Peri-urban & $9.8 \pm 17.2$ & $61.5 \pm 113$ & $29.3 \pm 23.0$ & $69.6 \pm 127$ & $11.6 \pm 27.0$ \\
Suburban & $24.2 \pm 50.5$ & $331 \pm 891$ & $7.8 \pm 22.8$ & $73.0 \pm 204$ & $5.6 \pm 9.0$ \\
Urban & & & & & \\
\hline
\end{tabular}

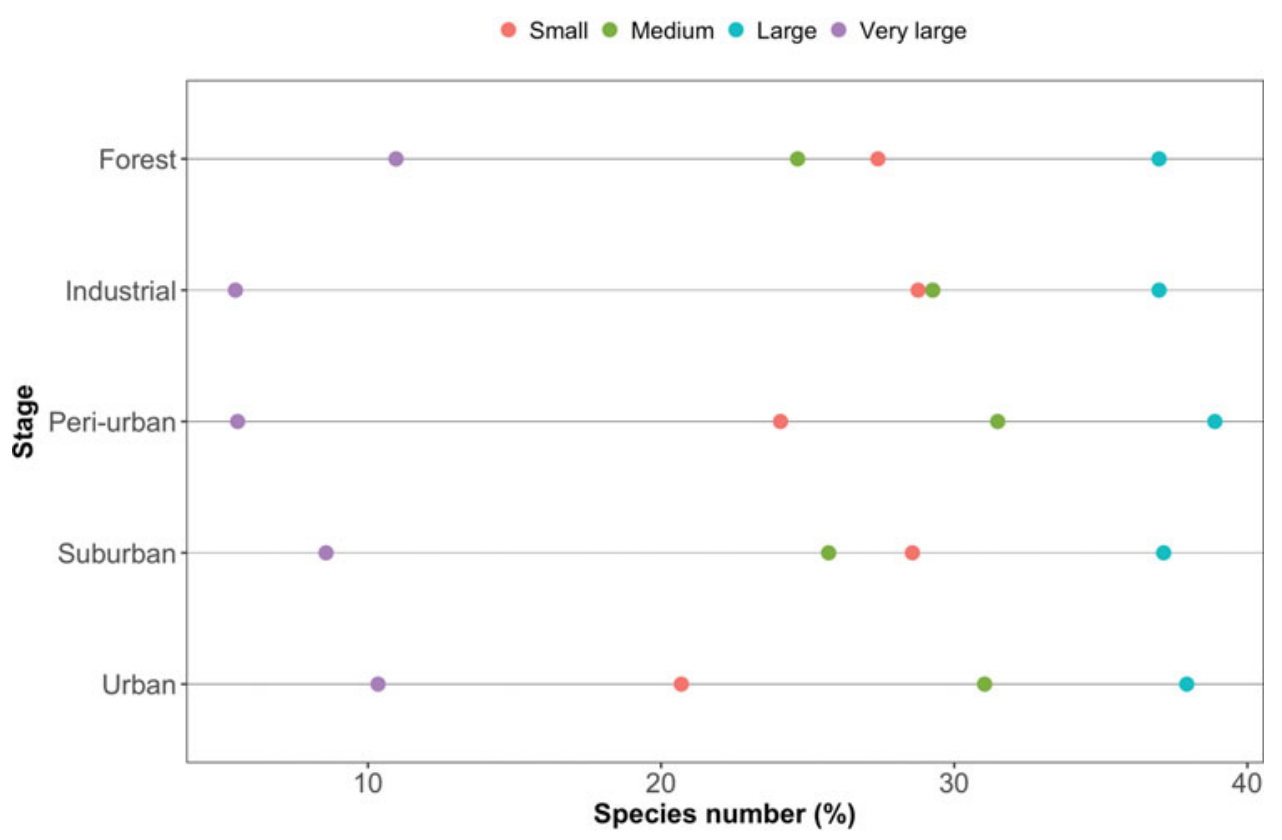

Figure 3. The composition by size classes of the bird assemblages along the five-stage urbanization gradient, observed during censuses in 20102013, in and around Amravati city, Maharashtra State, India.

(small $>$ medium $>$ large $>$ very large, Figure 3$)$. The foraging preference pattern was common to the gradient too (insectivores $>$ omnivores $>$ predators $>$ herbivores $>$ frugivores), with the only exception being the suburban stage (omnivores $>$ insectivores $>$ predators $>$ herbivores $>$ frugivores, Figure 4). Although forest and industrial areas had the same species richness, the proportion of foraging categories was different. We found more predatory and herbivorous species in the forest than in the industrial area ( 9 and 8 vs. 7 and 6 species, respectively), and more insectivorous and frugivorous ones in the industrial than forest area ( 33 and 5 vs. 31 and 3 species, respectively). Very large species were found mostly in the forest area, whereas in the industrial stage they were replaced by medium-sized species. The results of the logistic regression showed that species presence/absence was significantly affected by urbanization stage (Table 2). Species number in the rural forest area was significantly higher than in all the other stages (with the exception of the industrial area in 2010). Moreover, temporal effect in year 2011 and 2012 was observed independently of the urbanization stage. Bird abundance was significantly higher in the urban and suburban stages compared with all the others (Table 3).

The additive diversity partitioning indicated that of the overall diversity (gamma-diversity), alpha diversity (local diversity, i.e. at transect level) contributed 50.1\% to the total diversity. Only $2.7 \%$ was explained by between-transect differences, and the remaining 36.2\% by differences between urbanization stages. 


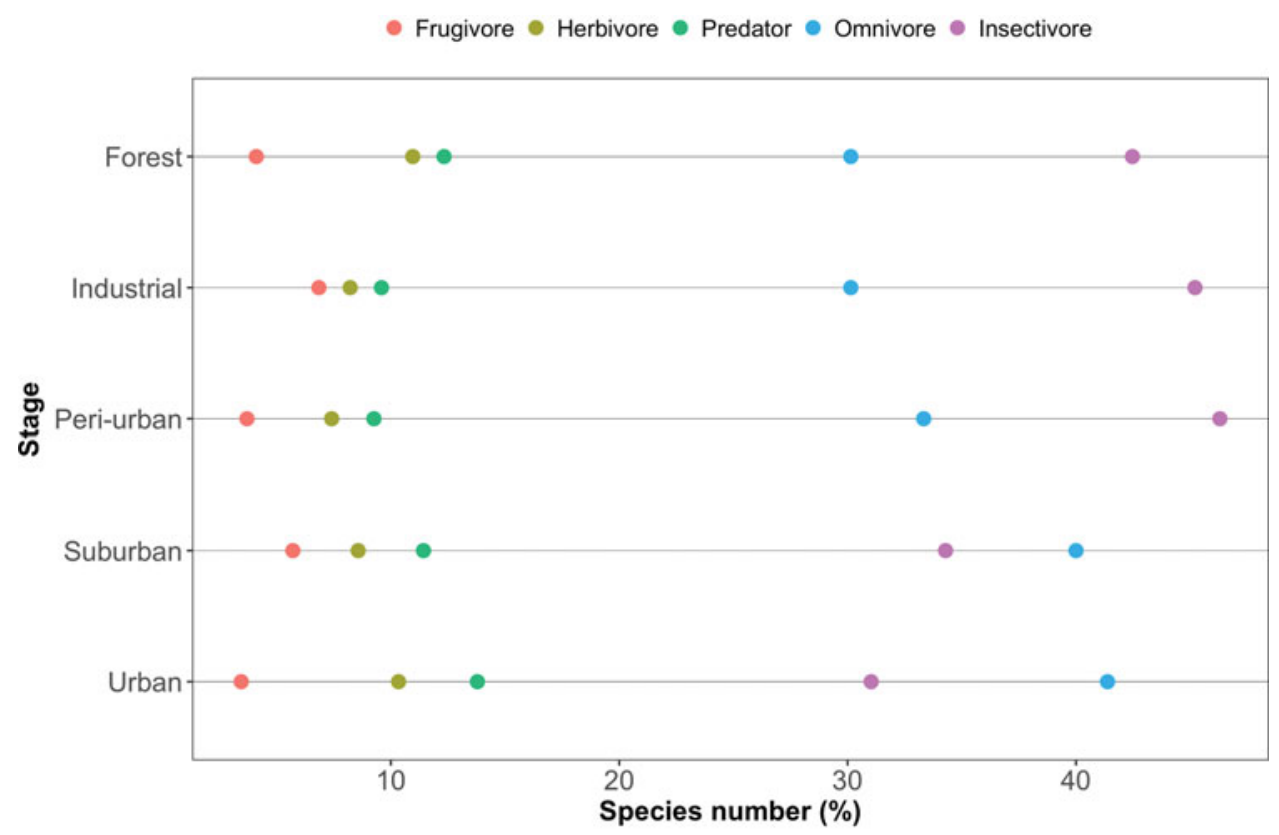

Figure 4. The composition by feeding categories of the bird assemblages along the five-stage urbanization gradient, observed during censuses in 2010-2013, in and around Amravati city, Maharashtra State, India.

Table 2. Summary results of the logistic regression for bird assemblages at Amravati city and surroundings, Maharashtra State, central India. The response variable of the model was presence/absence of species, and urbanization stage and year were fixed factors. Only significant values are shown.

\begin{tabular}{lrr}
\hline & Estimate & $\operatorname{Pr}(>|\mathrm{z}|)$ \\
\hline Intercept) & 0.65 & $<0.001$ \\
Peri-urban & -0.62 & $<0.001$ \\
Suburban & -1.24 & $<0.001$ \\
Urban & -1.43 & $<0.001$ \\
2011 & 0.35 & 0.035 \\
2012 & 0.35 & 0.035 \\
Industrial:2011 & -1.06 & $<0.001$ \\
Industrial:2012 & -1.12 & $<0.001$ \\
Industrial:2013 & -0.98 & $<0.001$ \\
\hline
\end{tabular}

Table 3. Summary result of the generalized linear model (Poisson family), with bird abundance as response variable, and urbanization stage as the fixed factor for the bird assemblages at Amravati city and surroundings, Maharashtra State, central India. Only significant values are shown.

\begin{tabular}{lcr}
\hline & Estimate & $\operatorname{Pr}(>|\mathrm{z}|)$ \\
\hline (Intercept) & 1.36 & $<0.001$ \\
Suburban & 0.48 & 0.008 \\
Urban & 0.80 & $<0.001$ \\
\hline
\end{tabular}

\section{DISCUSSION}

By using an urbanization gradient, we found that bird species richness was negatively affected by urbanization, while the opposite was true for bird abundance, which is in accordance with previous results (reviewed in Marzluff 2001). In this study, we provided evidence that this pattern is true also for tropical regions. We registered a higher species richness in general than found in similar studies in the temperate zone, which is not surprising, as India's avian biodiversity contains $13 \%$ of the world species richness, $\sim 1300$ species (Grimmett et al. 2001). The bird fauna of the various urbanization stages in this region originates from the rural bird fauna. Here we detected the effects of filtering mechanisms (Clergeau et al. 2006) that influenced the composition of bird assemblages in various urbanization stages.

We found support for H1, as the share of omnivorous and herbivorous species increased, both in terms of number of species and of individuals as urbanization progressed. The few species that are adapted to the overabundance of certain resources in urban centres will have a higher success than insectivores or predators as hypothesized. Although Galushin (1971) was impressed by the high number of predatory birds in New Delhi, he also commented on the very high numbers of the black kite (Milvus migrans), which are linked to carrion and rubbish, and that hunting birds are much more rare.

Consistently with our H2, large species were mostly restricted to the rural forest and in some cases, the industrial zones, and these hardly ever occurred in the more urbanized areas. This generated assemblages composed of smaller sized species - but still, the small insectivores (of which there are many in India, see Ali 2002) were lacking. One reason could be that the insect food supply could be smaller in urban settings. An indirect 
indication of this is the loss of large carabid beetle species, and the generally decreasing trend of species sizes along, for example, temperate forest urbanization gradients (Magura et al. 2010). Carabids form an important food resource for birds (Lövei \& Sunderland 1996), and trends found in this family could reflect the overall trends of arthropod sizes with increasing levels of urbanization.

Diversity partitioning indicated that local $(\alpha)$ diversity contributed $50.1 \%$ to the overall $(\gamma)$ diversity of 89 species identified in the region of study. Another 36.2\% was found at urbanization stage level and only $2.7 \%$ of the diversity was found at within-stage level $(\beta$ diversity), indicating fairly homogeneous assemblages. By partitioning $\beta$ diversity into components, we found species richness (species loss) was more important than species replacement for the pattern of $\beta$ diversity along the urban gradient. The urbanization in this region may create very similar conditions for birds, because the within-zone spatial variability contributed little to the overall pattern of diversity. Bird assemblages are strongly affected by habitat structure and availability of food. The supply of anthropogenic food in an urban centre and water in the gardens of residential suburban and peri-urban areas may contribute to bird richness (Blair 1996, McKinney 2002). Furthermore, structural biodiversity across urban parks and rural forest could also be important determinants (Diaz et al. 2005, Newton 1994).

The basis of such changes can be behavioural. The reactions of the Acadian flycatcher (Empidonax virescens) to urbanization in Ohio, USA, include higher levels of turnover in site occupancy, smaller-sized birds settling in urban areas, that show lower site fidelity and higher nest predation (Rodewald et al. 2013). This is probably true for between-species situations as well, but this hypothesis needs testing.

Our results could be extended by a systematic analysis of bird functional diversity in tropical areas, to test whether biotic homogenization also occurs under tropical conditions, and whether the reduced bird diversity would profoundly influence the functioning of urban ecosystems. With the continuing decline of biodiversity worldwide (Butchart et al. 2010), and the increasing urbanization, especially in the megadiverse regions of the world (Puppim de Oliveira et al. 2010), biodiversityfriendly management of urban areas could bring substantial global benefits.

\section{ACKNOWLEDGEMENTS}

We thank K. Morey, M. Nawarkhele and C. Shrivastav for help during fieldwork, C. H. Knudsen for preparing the map, and the anonymous reviewers for comments. Author contributions: MK, ND, RK and PB designed the study, fieldwork was performed by MK, ND and RK, data analysis by MF, IT, TI and GL and writing by MK, MF, IT and GL, with comments from the other authors. Authorship is by the first-and-last principle.

\section{LITERATURE CITED}

ALI, S. 2002. The book of Indian birds. (Thirteenth, revised edition). Bombay Natural History Society, Mumbai. 354 pp.

AHRNÉ, K., BENGTSSON, J. \& ELMQVIST, T. 2009. Bumble bees (Bombus spp.) along a gradient of increasing urbanization. PLOS ONE 4:e5574.

ANDERSON, M. J., CRIST, T. O., CHASE, J. M., VELLEND, M., INOUYE, B. D., FREESTONE, A. L., SANDERS, N. J., CORNELL, H. V., COMITA, L. S., DAVIES, K. F., HARRISON, S. P., KRAFT, N. J. B., STEGEN, J. \& SWENSON, N. G. 2011. Navigating the multiple meaning of $\beta$ diversity: a roadmap for the practicing ecologist. Ecology Letters 14:19-28.

ARONSON, M. F. J., LA SORTE, F. A., NILON, C. H., KATTI, M., GODDARD, M. A., LEPCZYK, C.A., WARREN, P. S., WILLIAMS, N. S. G., CILLIERS, S., CLARKSON, B., DOBBS, C., DOLAN, R., HEDBLOM, M., KLOTZ, S., KOOIJMANS, J. L., KÜHN, I., MACGREGOR-FORS, I., MCDONNELL, M., MÖRTBERG, U., PYŠEK, P., SIEBERT, S., SUSHINSKY, J., WERNER, P. \& WINTER, M. 2014. A global analysis of the impacts of urbanization on bird and plant diversity reveals key anthropogenic drivers. Proceedings of the Royal Society B 281:20133330.

BARKER, R. J., SCHOFIELD, M. R., LINK, W. A. \& SAUER, J. R. 2017. On the reliability of $\mathrm{N}$-mixture models for count data. Biometrics 74:369-377.

BLAIR, R. B. 1996. Land use and avian species diversity along an urban gradient. Ecological Applications 6:506-519.

BUTCHART, S. H. M., WALPOLE, M., COLLEN, B., VAN STRIEN, A., SCHARLEMANN, J.P.W., ALMOND, R.E. A., BAILLIE, J.E. M., BOMHARD, B., BROWN, C., BRUNO, J., CARPENTER, K. E., CARR, G. M., CHANSON, J., CHENERY, A. M., CSIRKE, J., DAVIDSON, N. C., DENTENER, F., FOSTER, M., GALLI, A., GALLOWAY, J. N., GENOVESI, P., GREGORY, R.D., HOCKINGS, M., KAPOS, V., LAMARQUE, J.F. ET AL. 2010. Global biodiversity: indicators of recent declines. Science 328:1164-1168.

CARDILLO, M., MACE, G. M., JONES, K.E., BIELBY, J., BININDAEMONDS, O. R. P., SECHREST, W. \& ORME, D. L. 2005. Multiple causes of high extinction rate in large mammal species. Science 309:1239-1241.

CHACE, J. F. \& WALSH, J. J. 2006. Urban effects on native avifauna: a review. Landscape Urban Planning 74:46-69.

CHAMPION, H. G. \& SETH, K. S. 1968. A revised survey of the forest types of India. Government of India Press, New Delhi. 404 pp.

CHAZDON, R. L., PERES, C. A., DENT, D., SHEIL, D., LUGO, A. E., LAMB, D., STORK, N.E. \& MILLER, S. 2009. The potential for species conservation in tropical secondary forests. Conservation Biology 23:1406-1417.

CLERGEAU, P., SAVARD, J.-P. L., MENNECHEZ, G. \& FALARDEAU, G. 1998. Bird abundance and diversity along an urban-rural gradient: 
a comparative study between two cities on different continents. The Condor 100:413-425.

CLERGEAU, P., CROCI, S., JOKIMÄKI, J., KAISANLAHTI-JOKIMÄKI, M-L \& DINETTI, M. 2006. Avifauna homogenisation by urbanisation: analysis at different European latitudes. Biological Conservation 127:336-344.

CRIST, T. O. \& VEECH, J. A. 2006. Additive partitioning of rarefaction curves and species-areas relationships: unifying $\alpha-, \beta$ - and $\gamma$ diversity with sample size and habitat area. Ecology Letters 9:923932.

DIAZ, I. V., ARMESTO, J. J., REID, S., SIEVING, K. E. \& WILLSON, M. F. 2005. Linking forest structure and composition: avian diversity in successional forests of Chiloé Island, Chile. Biological Conservation 123:91-101.

DUARTE, A., ADAMS, M. J., PETERSON, J. T. 2018. Fitting N-mixture models to count data with unmodeled heterogeneity bias, diagnostics, and alternative approaches. Ecological Modelling 374:5159.

EIGENBROD, F., BELL, V. A., DAVIES, H. N., HEINEMYER, A., ARMSWORTH, P. R. \& GASTON, K. J. 2011. The impact of projected increases in urbanization on ecosystem services. Proceedings of the Royal Society B 278: 2301-2308.

ELEK, Z. \& LÖVEI, G. L. 2007. Patterns in ground beetle (Coleoptera: Carabidae) assemblages along an urbanisation gradient in Denmark. Acta Oecologica 32:104-111.

FERRANTE, M., LO CACCIATO, A. \& LÖVEI, G. L. 2014. Quantifying predation pressure along an urbanisation gradient in Denmark using artificial caterpillars. European Journal of Entomology 111:649-654.

GALUSHIN, W. M. 1971. A huge urban population of birds of prey in Delhi, India. Ibis 113:522.

GIBSON, L., LEE, T. M., KOH, L. P., BROOK, B. W., GARDNER, T. A., BARLOW, J., PERES, C. A., BRADSHAW, C. J. A., LAURANCE, W. F., LOVEJOY, T. E. \& SODHI, N. S. 2011. Primary forests are irreplaceable for sustaining tropical biodiversity. Nature 478:378-383.

GRIMMETT, R., INSKIPP, C. \& INSKIPP, T. 2001. Pocket guide to the birds of the Indian Subcontinent. Oxford University Press, New Delhi. 384 pp.

HENDERSON, P. A. \& SOUTHWOOD, T. R. E. 2016. Ecological methods. (Fourth edition). John Wiley \& Son, Chichester. 632 pp.

HUSTON, M. A. 1994. Biological diversity. Cambridge University Press, Cambridge. 682 pp.

IZENMAN, A. J. 2008. Modern multivariate statistical techniques. Regression, classification and manifold learning. Springer, Berlin. 740 pp.

JOKIMÄKI, J. \& SUHONEN, J. 1993. Effects of urbanization on the breeding bird species richness in Finland: a biogeographical comparison. Ornis Fennica 70:71-77.

LANDE, R. 1996. Statistics and partitioning of species diversity, and similarity among multiple communities. Oikos 76:5-13.

LIKER, A., PAPP, Z., BÓKONY, V. \& LENDVAI, Á. Z. 2008. Lean birds in the city: body size and condition of house sparrows along the urbanization gradient. Journal of Animal Ecology 77:789-795.

LIN, Y.-P., CHANG, C.-R., CHU, H.-J. \& CHENG, B.-Y. 2011. Identifying the spatial mixture distribution of bird diversity across urban and suburban areas in the metropolis: a case study in Taipei Basin of Taiwan. Landscape and Urban Planning 102:156-163.
LÖVEI, G. L. \& SUNDERLAND, K. D. 1996. The ecology and behaviour of ground beetles. Annual Review of Entomology 41:231-256.

MACGREGOR-FORS, I. 2008. Relation between habitat attributes and bird richness in a western Mexico suburb. Landscape and Urban Planning 84:92-98.

MAGURA, T., LÖVEI, G. L. \& TÓTHMÉRÉSZ, B. 2010. Does urbanisation decrease diversity in ground beetle (Carabidae) assemblages? Global Ecology and Biogeography 19:16-26.

MAGURRAN, A.E. 2003. Measuring biological diversity. Blackwell Publishing, Oxford. 264 pp.

MARZLUFF, J. M. 2001. Worldwide urbanization and its effects on birds. Pp. 19-47 in Marzluff, J. M., Bowman, R. \& Donnelly, R. (eds). Avian ecology in an urbanizing world. Kluwer Academic Publishers, Norwell.

MARZLUFF, J. M. 2005. Island biogeography for an urbanizing world: how extinction and colonization may determine biological diversity in human-dominated landscapes. Urban Ecosystems 8:157-177.

MCKINNEY, M. L. 2002. Urbanization, biodiversity and conservation. Bioscience 52:883-890.

MCKINNEY, M. L. 2006. Urbanization as a major cause of biotic homogenization. Biological Conservation 127:247-260.

MCKINNEY, M. L. 2008. Effects of urbanization on species richness: a review of plants and animals. Urban Ecosystems 11:161-176.

MILLENNIUM ECOSYSTEM ASSESSMENT 2005. Ecosystem and human well-being: synthesis. Island Press, Washington, DC. 155 pp.

NEWTON, I. 1994. The role of nest sites in limiting the numbers of hole nesting birds: a review. Biological Conservation 70:265-276.

PETERS, R. H. 1986. The ecological implications of body size. Cambridge University Press, Cambridge. 329 pp.

PICKETT, S. T., CADENASSO, M., GROVE, J., NILON, C., POUYAT, R., ZIPPERER, W. \& COSTANZA, R. 2001. Urban ecological systems: linking terrestrial ecological, physical, and socioeconomic components of metropolitan areas. Annual Review of Ecology and Systematics 32:127-157.

PUPPIM DE OLIVEIRA, J. A., BALABAN, O., DOLL, C. N. H., MORENOPEÑARANDA, R., GASPARATOS, A., IOSSIFOVA, D. \& SUWA, A. 2010. Cities and biodiversity: perspectives and governance challenges for implementing the Convention on Biological Diversity (CBD) at the city level. Biological Conservation 144:1302-1313.

RODEWALD, A. D., KEARNS, L. J. \& SHUSTACK, D. P. 2013. Consequences of urbanizing landscapes to reproductive performance of birds in remnant forests. Biological Conservation 160:32-39.

SENGUPTA, S., MONDAL, M. \& BASU, P. 2014. Bird species assemblages across a rural urban gradient around Kolkata, India. Urban Ecosystems 17:585-596.

SOL, D., GONZÁlEZ-LAGOS, C., MOREIRA, D., MASPONS, J. \& LAPIEDRA, O. 2014. Urbanisation tolerance and the loss of avian diversity. Ecology Letters 17:942-950.

UNITED NATIONS. 2014. World urbanization prospects: the 2014 revision. Highlights. (ST/ESA/SER.A/352). United Nations, New York. $32 \mathrm{pp}$.

VERNER, J. 1985. Assessment of counting techniques. Current Ornithology 2:247-302.

WAGNER, L. N. (ed.) 2008. Urbanization: 21st century issues and challenges. Nova Science Publishers, New York. 242 pp. 
WILMAN, H., BELMAKER, J., SIMPSON, J., DE LA ROSA, C., RIVADENEIRA, M. M. \& JETZ, W. 2014. EltonTraits 1.0: species-level foraging attributes of the world's birds and mammals. Ecology 95:2027.
ZUUR, A. F., IENO, E. I., WALKER, N. J. \& SAVELIEV, A. 2009. GML and GAM for count data. Pp. 209-243 in Gail, M., Krickeberg, K., Samet, J. M., Tsiatis, A. \& Wong, W. (eds). Mixed effects models and extensions in ecology with R. Springer Science and Business Media, New York.

Appendix 1. List of the birds observed along the urbanization gradient in Amravati city, Maharashtra State, central India, with their food preferences, and body size class. Species nomenclature follows Ali (2002). Food preference and body size extracted from Wilman et al. (2014). Body size classes: small (6-45 g), medium (45-120 g), large (120-300 g) and very large (>300 g).

\begin{tabular}{|c|c|c|c|c|}
\hline Family & Species & Status & Food preference & Body size class \\
\hline Phasianidae & Francolinus pondicerianus & Resident & Omnivore & Large \\
\hline Phasianidae & Francolinus pictus & Resident & Omnivore & Large \\
\hline Phasianidae & Pavo cristatus & Resident & Omnivore & Very large \\
\hline Picidae & Jynx torquilla & Resident & Insectivore & Small \\
\hline Picidae & Dinopium benghalense & Resident & Insectivore & Medium \\
\hline Megalaimidae & Megalaima haemacephala & Resident & Omnivore & Small \\
\hline Bucerotidae & Ocyceros birostris & Resident & Omnivore & Very large \\
\hline Upupidae & Uрира ерорs & Resident & Insectivore & Medium \\
\hline Coraciidae & Coracias benghalensis & Resident & Insectivore & Large \\
\hline Halcyonidae & Halcyon smyrnensis & Resident & Predator & Medium \\
\hline Meropidae & Merops orientalis & Resident & Insectivore & Small \\
\hline Cuculidae & Clamator jacobinus & Winter migrant & Omnivore & Medium \\
\hline Cuculidae & Hierococcyx varius & Resident & Insectivore & Medium \\
\hline Cuculidae & Cacomantis passerinus & Resident & Insectivore & Small \\
\hline Cuculidae & Eudynamys scolopacea & Resident & Frugivore & Large \\
\hline Centropodidae & Centropus sinensis & Resident & Insectivore & Large \\
\hline Psittacidae & Psittacula eupatria & Resident & Herbivore & Large \\
\hline Psittacidae & Psittacula krameri & Resident & Herbivore & Medium \\
\hline Psittacidae & Psittacula cyanocephala & Resident & Herbivore & Medium \\
\hline Apodidae & Apus affinis & Resident & Insectivore & Small \\
\hline Strigidae & Athene brama & Resident & Predator & Medium \\
\hline Caprimulgidae & Caprimulgus asiaticus & Resident & Insectivore & Small \\
\hline Columbidae & Columba livia & Resident & Omnivore & Very large \\
\hline Columbidae & Treron phoenicoptera & Resident & Frugivore & Large \\
\hline Columbidae & Streptopelia decaocto & Resident & Frugivore & Large \\
\hline Columbidae & Streptopelia tranquebarica & Resident & Frugivore & Medium \\
\hline Columbidae & Streptopelia chinensis & Resident & Herbivore & Large \\
\hline Columbidae & Streptopelia senegalensis & Resident & Omnivore & Medium \\
\hline Pteroclidae & Pterocles indicus & Resident & Herbivore & Large \\
\hline Burhinidae & Burhinus oedicnemus & Resident & Insectivore & Very large \\
\hline Charadriidae & Vanellus malabaricus & Resident & Insectivore & Large \\
\hline Charadriidae & Vanellus indicus & Resident & Insectivore & Large \\
\hline Accipitridae & Elanus caeruleus & Resident & Predator & Large \\
\hline Accipitridae & Milvus migrans & Resident & Predator & Very large \\
\hline Accipitridae & Accipiter badius & Resident & Predator & Large \\
\hline Accipitridae & Circaetus gallicus & Resident & Predator & Very large \\
\hline Accipitridae & Pernis ptilorhyncus & Resident & Insectivore & Very large \\
\hline Accipitridae & Butastur teesa & Resident & Predator & Very large \\
\hline Falconidae & Falco tinnunculus & Resident & Predator & Large \\
\hline Laniidae & Lanius excubitor & Resident & Insectivore & Medium \\
\hline Laniidae & Lanius vittatus & Resident & Insectivore & Small \\
\hline Laniidae & Lanius schach & Resident & Insectivore & Medium \\
\hline Corvidae & Corvus splendens & Resident & Omnivore & Very large \\
\hline Corvidae & Pericrocotus cinnamomeus & Resident & Insectivore & Small \\
\hline Corvidae & Pericrocotus erythropygius & Resident & Insectivore & Small \\
\hline Corvidae & Dicrurus macrocercus & Resident & Insectivore & Medium \\
\hline Corvidae & Rhipidura aureola & Resident & Insectivore & Small \\
\hline Corvidae & Terpsiphone paradisi & Resident & Insectivore & Small \\
\hline Corvidae & Aegithina tiphia & Resident & Insectivore & Small \\
\hline Muscicapidae & Monticola solitarius & Winter Migrant & Insectivore & Medium \\
\hline Muscicapidae & Ficedula parva & Winter Migrant & Omnivore & Small \\
\hline
\end{tabular}


Appendix 1. Continued

\begin{tabular}{|c|c|c|c|c|}
\hline Family & Species & Status & Food preference & Body size class \\
\hline Muscicapidae & Copsychus saularis & Resident & Insectivore & Small \\
\hline Muscicapidae & Saxicoloides fulicata & Resident & Insectivore & Small \\
\hline Muscicapidae & Phoenicurus ochruros & Winter Migrant & Omnivore & Small \\
\hline Muscicapidae & Saxicola caprata & Resident & Insectivore & Small \\
\hline Muscicapidae & Cercomela fusca & Resident & Insectivore & Small \\
\hline Sturnidae & Sturnus pagodarum & Resident & Omnivore & Medium \\
\hline Sturnidae & Sturnus roseus & Winter Migrant & Omnivore & Medium \\
\hline Sturnidae & Sturnus contra & Resident & Omnivore & Medium \\
\hline Sturnidae & Acridotheres tristis & Resident & Omnivore & Medium \\
\hline Hirundinidae & Hirundo concolor & Resident & Insectivore & Small \\
\hline Hirundinidae & Hirundo smithii & Resident & Insectivore & Small \\
\hline Pycnonotidae & Pycnonotus cafer & Resident & Omnivore & Small \\
\hline Cisticolidae & Cisticola juncidis & Resident & Insectivore & Small \\
\hline Cisticolidae & Prinia sylvatica & Resident & Insectivore & Small \\
\hline Cisticolidae & Prinia socialis & Resident & Insectivore & Small \\
\hline Cisticolidae & Prinia inornata & Resident & Insectivore & Small \\
\hline Zosteropidae & Zosterops palpebrosus & Resident & Frugivore & Small \\
\hline Sylviidae & Orthobomus sutorius & Resident & Omnivore & Small \\
\hline Sylviidae & Chrysomma sinense & Resident & Omnivore & Small \\
\hline Sylviidae & Turdoides caudatus & Resident & Omnivore & Small \\
\hline Sylviidae & Turdoides malcolmi & Resident & Omnivore & Medium \\
\hline Sylviidae & Turdoides striatus & Resident & Omnivore & Medium \\
\hline Alaudidae & Eremopterix grisea & Resident & Omnivore & Small \\
\hline Alaudidae & Ammomanes phoenicurus & Resident & Insectivore & Small \\
\hline Alaudidae & Mirafra cantillans & Resident & Omnivore & Small \\
\hline Nectarinidae & Nectarinia zeylonica & Resident & Herbivore & Small \\
\hline Nectarinidae & Nectarinia asiatica & Resident & Herbivore & Small \\
\hline Passeridae & Motacilla alba & Winter Migrant & Insectivore & Small \\
\hline Passeridae & Motacilla cinerea & Winter Migrant & Insectivore & Small \\
\hline Passeridae & Motacilla madaraspatensis & Resident & Insectivore & Small \\
\hline Passeridae & Anthus rufulus & Resident & Insectivore & Small \\
\hline Passeridae & Passer domesticus & Resident & Omnivore & Small \\
\hline Passeridae & Petronia xanthocollis & Resident & Omnivore & Small \\
\hline Passeridae & Ploceus philippinus & Resident & Omnivore & Small \\
\hline Passeridae & Lonchura malabarica & Resident & Herbivore & Small \\
\hline Fringillidae & Melophus lathami & Resident & Omnivore & Small \\
\hline Accipitridae & Circus macrourus & Winter Migrant & Predator & Very large \\
\hline Accipitridae & Dendrocitta vagabunda & Resident & Omnivore & Medium \\
\hline
\end{tabular}

